\title{
NONLINEAR FILTRATION LAWS OF ONE-COMPONENT FLUIDS AT HIGH FLOW RATES
}

\author{
. . олп ев, . . хмедов, . • оголев \\ V. A. Tolpaev, K. S. Akhmedov, S. A. Gogoleva
}

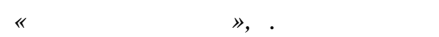

лючевые слов : $з$ кон рси; з кон орхгеймер ; көон рри- онвея; д вление; дин мическ я вязкость; прониц емость; эффективн я прониц емость; число ейнольдс ; ппроксим ция Key words: Darcy law; Forchheimer law; Barry Conway law; pressure; dynamic viscosity; Permeability; effective permeability; Reynolds number; approximation

первые систем тические эксперимент льные исследов ния з кономерностей фильтр ции однокомпонентных жидкостей в пористых сред х проводил в середине XIX век фр нцузский инженер-гидр влик нри илибер сп $\mathrm{p}$ рси. езульт том этих исследов ний является ур внение, связыв ющее скорость фильтр ции $\vec{v}$ с гр диентом д вления $p$, н зыв емое з коном рси и которое в современных обозн чениях для случ я фильтр ции г 3 , когд сил ми тяжести по ср внению с поверхностными сил ми д вления пренебрег ют, 3 писыв ется в виде [1]

$$
-\operatorname{grad} p=\frac{\mu \cdot \vec{v}}{k}
$$

где $\boldsymbol{\mu}$ - коэффициент дин мической вязкости г з,$k-$ прониц емость пористой среды.

случ е фильтр ции весомой жидкости (воды, нефти) в ур внении (1) вместо гидродин мического д вления $p$ следует з писыв ть приведенное д вление $P=p+\rho \cdot g \cdot z+C[1]$. этой сумме $\rho \cdot g \cdot z$ предст вляет потенци л м ссовой силы тяжести, действующей н флюид со стороны емли, $z$ - пплик т точки н блюдения, отсчитыв ем я вдоль н пр вленной вверх вертик льной оси, $p$ - плотность флюид и $g$ - ускорение свободного п дения. ретье сл г емое $C$ - произвольн я ддитивн я постоянн я, зн чение которой определяется н зн чением величины приведенного д вления н нивелировочной плоскости, то есть плоскости отсчет,$z=0$.

иже для конкретности будем подр зумев ть случ й фильтр ции г 3 , и в ур внениях применять только гидродин мическое д вление $p$.

олее поздние и более точные эксперимент льные исследов ния пок з ли, что з кон рси не универс лен и имеет свои гр ницы применимости, которые уст н влив ются по зн чению безр змерного фильтр ционного числ ейнольдс , определяемого формулой [1]

\section{№ 5,2015}

ефть и г 3 


$$
\operatorname{Re}=\frac{\rho \cdot v \cdot \sqrt{k}}{\mu} .
$$

3 коне (1) коэффициент прониц емости $k$ х р ктеризует пропускную способность пористой среды при дост точно м лых зн чениях числ ейнольдс $\operatorname{Re}=\frac{\rho \cdot v \cdot \sqrt{k}}{\mu}$, не превыш ющих некоторого критического зн чения $\mathrm{Re}_{\mathrm{kp}}$. ля уменьшения погрешностей з кон рси при больших скоростях фильтр ции введем в (1) безр змерный попр вочный множитель $f(\operatorname{Re})$, с помощью которого з кон фильтр ции г з для больших скоростей предст вим в виде

$$
-\operatorname{grad} p=f(\operatorname{Re}) \cdot \frac{\mu \cdot \vec{v}}{k}=\frac{\mu \cdot \vec{v}}{k_{\text {эфф }}} .
$$

ур внении (3) с целью эксперимент льного определения попр вочного множителя $f(\operatorname{Re})$ применяются, следуя . . рри и . . онвей [2, 3], понятия эффективной прониц емости $k_{\text {эфф }}$ и прониц емости $k$ рси. рониц емостью $k$ рси выбр нного обр зц пористой среды н зыв ется измеренное опытным путем зн чение прониц емости н режиме фильтр ции с некоторым м лым 3 фиксиров нным числом ейнольдс

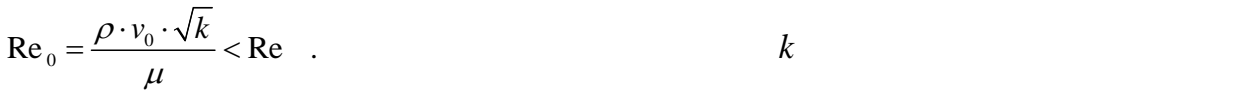
среды н зыв ется измеренное опытным путем зн чение прониц емости н режиме фильтр ции с другим числом ейнольдс $\operatorname{Re}=\frac{\rho \cdot v \cdot \sqrt{k}}{\mu}>\operatorname{Re}_{\text {кр }}$. сли провести серию опытов, и в к ждом р ссчит ть отношение прониц емости рси $k$ к эффективной прониц емости $k_{\text {эфф }}$ исследуемого обр зц пористой среды, то в результ те получим т блично з д нную функцию

$$
\frac{k}{k_{\text {эф巾 }}}=f(\mathrm{Re}) \text {. }
$$

3 общего нелинейного з кон фильтр ции (3) вытек ют к к ч стные случ и все известные з коны фильтр ции. сли в ур внениях (3) и (4) функция $f(\operatorname{Re}) \equiv 1$, получим кл ссический з кон линейной фильтр ции - 3 кон рси (1). сли попр вочный множитель $f(\mathrm{Re})$ линейно з висит от числ ейнольдс $f(\mathrm{Re})=1+\beta \cdot \operatorname{Re}$, получим другой кл ссический ч стный случ й — 3 кон нелинейной фильтр ции орхгеймер [1]

$$
-\operatorname{grad} p=\left(1+\beta \cdot \frac{\rho \cdot v \cdot \sqrt{k}}{\mu}\right) \cdot \frac{\mu \cdot \vec{v}}{k}=\frac{\mu \cdot \vec{v}}{k}+\beta \cdot \frac{\rho \cdot v}{\sqrt{k}} \cdot \vec{v} .
$$

ля уменьшения погрешностей при больших скоростях фильтр ции двучленного 3 кон орхгеймер (5) . . рри и . . онвей $[2,3,4]$ предложили новую модель, содерж щую кроме п р метров $k$ и $\beta$ дв дополнительных п р метр $k_{m r}$ и $\alpha$ :

$$
\frac{k}{k_{\text {эф巾 }}}=f(\operatorname{Re})=\frac{(1+\beta \cdot \operatorname{Re})^{\alpha}}{k_{m r} \cdot(1+\beta \cdot \operatorname{Re})^{\alpha}+1-k_{m r}} .
$$

р метр $k_{m r}$ в (6) может приним ть зн чения от нуля до единицы включительно, $\alpha$ приним ет положительные зн чения. з ур внения (6) видно, что если $k_{m r}=0$ и пок $3-$ тель степени $\alpha=1$, то (6) приводит к кл ссическому ур внению орхгеймер (5). сли $k_{m r}=1$, то (6) приводит к линейному з кону рси (1).

уршиным . . в им. профессор . . уковского проводились эксперимент льные исследов ния эффективной прониц емости пористых мет ллов, волоконных м тери лов, гр фитов, обр зцов горных пород при сверхвысоких гр диент х д влений до 
1,5 / мм. огл сно его исследов ниям $[5,6,7]$, з висимость $\frac{k}{k_{\text {эфф }}}$ можно опис ть функциями, линейно з висящими от числ ейнольдс

$$
\frac{k}{k_{\text {эф巾 }}}=f(\operatorname{Re})=a+b \cdot \operatorname{Re}=a+b \cdot \frac{\rho \cdot v \cdot \sqrt{k}}{\mu} .
$$

дн ко с тем уточнением, что п р метры $a$ и $b$ н $\mathrm{p}$ зных уч стк х изменения числ ейнольдс определяются р злично. н литически з висимость коэффициентов $a$ и $b$ от числ $\operatorname{Re}=R$, согл сно эксперимент льным исследов ниям уршин . ., можно предст вить следующим обр зом:

$$
a=\left\{\begin{array}{lll}
a_{1}=\text { const } & \text { при } & R \leq R_{1}, \\
a_{2}=a_{1}+\frac{a_{3}-a_{1}}{R_{2}-R_{1}} \cdot\left(R-R_{1}\right) & \text { при } & R_{1} \leq R \leq R_{2}, \\
a_{3}=\text { const } & \text { при } & R \geq R_{2} ;
\end{array}\right.
$$

$$
b= \begin{cases}0 & \text { при } \quad R \leq R_{1}, \\ b_{2}=\frac{b_{3}}{R_{2}-R_{1}} \cdot\left(R-R_{1}\right) & \text { при } R_{1} \leq R \leq R_{2}, \\ b_{3}=\text { const } & \text { при } R \geq R_{2} .\end{cases}
$$

ри м лых скоростях фильтр ции, когд $\mathrm{Re} \leq R_{1}$, коэффициент прониц емости, по эксперимент льным д нным уршин . ., не з висит от числ ейнольдс, и имеет место линейн я фильтр ция по з кону рси. о второй обл сти $R_{1} \leq \operatorname{Re} \leq R_{2}$, с ростом скорости фильтр ции коэффициенты $a$ и $b$ возр ст ют до своих м ксим льных зн чений $a_{3}$ и $b_{3}$. тор я обл сть - это обл сть переходного режим от л мин рного к турбулентному режиму течения. третьей обл сти $\operatorname{Re} \geq R_{2}$, по д нным уршин . ., коэффициенты $a$ и $b$ ост ются неизменными, р вными м ксим льным, что ук зыв ет н сохр нение турбулентного х $\mathrm{p}$ ктер течения для больших чисел $\operatorname{Re} \geq R_{2}$.

глядную х р ктеристику предст вленных эксперимент льных з конов нелинейной фильтр ции д ют гр фики з висимостей $\frac{k}{k_{\text {эф巾 }}}$ н рис. 1.

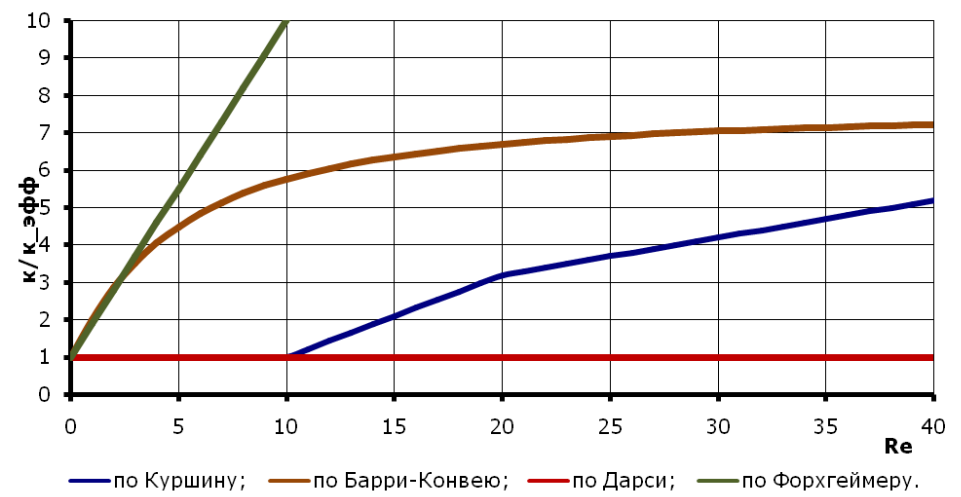

ис. 1. р внение з висимостей $\frac{k}{k_{\vartheta \phi \phi}}$ от числ ейнольдс дляр зличных з конов фильтр ци

з предст вленных гр фиков, во-первых, видно, что н режим х фильтр ции с м лыми числ ми ейнольдс з коны орхгеймер и рри- онвея пр ктически один ково описыв ют пропускную способность пористой среды. ким обр зом, для режимов фильтр ции с м лыми числ ми ейнольдс р зумно применять в р счет х потоков более простой кл ссический з кон орхгеймер . о-вторых, видно, что с ростом скорости фильтр ции (с увели- 
чением числ ейнольдс ) пропускн я способность пористой среды, количественно выр ж ем я зн чением эффективной прониц емости $k_{э \phi \phi}$, п д ет. о з кону рри- онвея эффективн я прониц емость $k_{э ф \phi ~}$ симптотически п д ет до некоторого миним льного

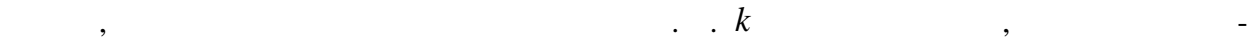
лениям . . рри и . . онвея является непр вильным. рис. 2 отдельно предст влен х р ктер изменения пропускной способности пористой среды по з кону рри- онвея при р зличных зн чениях п р метр $\alpha$ и при з фиксиров нном п р метре $k_{m r}=0,09$.

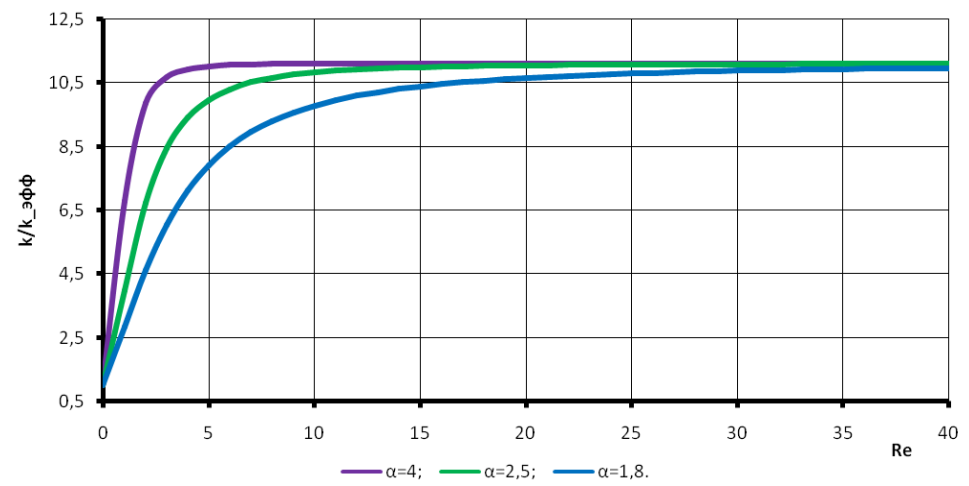

ис. 2. лияниен пропускную способность пористой среды поз кону рри- онвея n р метр $\alpha$ приз фиксиров нном $\boldsymbol{n}$ р метре $k_{m r}=0,09$

рис. 3 предст влен х р ктер изменения пропускной способности пористой среды по 3 кону рри- онвея при р зличных зн чениях п р метр $k_{m r}$ при з фиксиров нном п р метре $\alpha=2$.

ис. 2, 3 снов подтвержд ют, что н режим х фильтр ции с м лыми числ ми ейнольдс 3 коны орхгеймер и рри- онвея почти один ково описыв ют пропускные способности пористой среды. ис. 2, 3 помог ют понять физический смысл новых введенных . . рри и . . онвеем фильтр ционных п р метров $k_{m r}$ и $\alpha$.

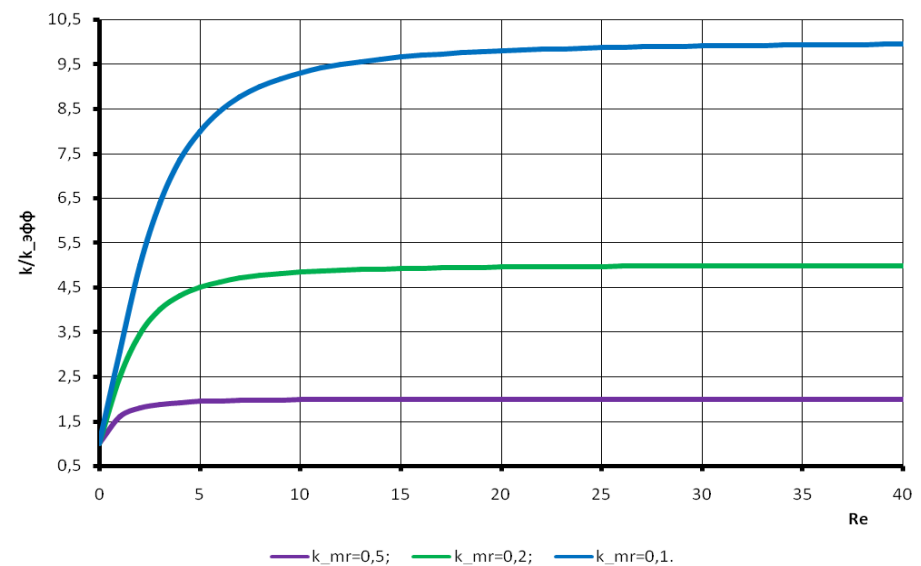

ис. 3. лияние поз кону рри- онвея н пропускную способность пористой среды п р метр $k_{m r}$ приз фиксиров нном п р метре $\alpha=2$

з них и из формулы (6) видно, что физический смысл п р метр $k_{m r}$ в том, что он $3-$ д ет предельное миним льное зн чение пропускной способности пористой среды при высо-

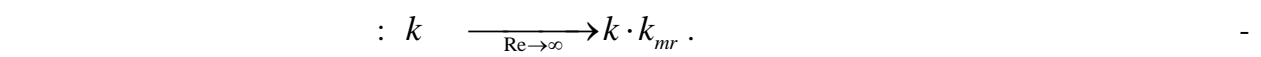
ский смысл п р метр $\alpha . \quad$ р метр $\alpha$ д д ет скорость п дения пропускной способности 
пористой среды: чем больше $\alpha$, тем быстрее п д ет пропускн я способность пористой среды, и эффективн я прониц емость быстрее приближ ется к своей симптотической миним льной величине.

ким обр зом, . . рри, . . онвей и уршин . . эксперимент льно док з ли, что пропускн я способность пористой среды, количественно определяем я эффективной прониц емостью $k_{э ф \phi ~}$, уменьш ется с ростом фильтр ционного числ ейнольдс по определенному з кону. иболее естественной з висимостью $\frac{k}{k_{\text {эфф }}}=f(\operatorname{Re})$ для всех прониц емых пористых сред служит з кон рри- онвея (6). едост тком з кон рри- онвея (6) является то, что непосредственно применить его для определения п р метров $k, \beta, k_{m r}$ и $\alpha$ н основе результ тов г зогидродин мических исследов ний скв жин ( ) весьм 3 труднительно. оэтому возник ет кту льн я для пр ктики з д ч преобр зов ть $з$ кон

рри- онвея (6) т к, чтобы модифициров нный з кон позволял строить удобные для обр ботки д нных м тем тические модели приток г 3 к скв жине. приемлемой точностью в этом случ е для ди п зон пр ктических зн чений чисел ейнольдс [8] можно рекомендов ть применение полиноми льных ппроксим ций з кон рри- онвея (6) в виде

$$
\frac{k}{k_{\text {sक्ष }}}=f(\mathrm{Re}) \approx 1+c_{1} \cdot \mathrm{Re}+c_{2} \cdot \mathrm{Re}^{2}+c_{3} \cdot \mathrm{Re}^{3}+c_{4} \cdot \mathrm{Re}^{4}+c_{5} \cdot \mathrm{Re}^{5}+\ldots
$$

ри н личии полиноми льных ппроксим ций з кон рри- онвея (6) общее ур внение (3) нелинейной фильтр ции г 3 для больших скоростей будет предст вляться в виде

$$
-\operatorname{grad} p=\left[\sum_{m=0}^{n} c_{m} \cdot(\operatorname{Re})^{m}\right] \cdot \frac{\mu \cdot \vec{v}}{k} .
$$

оложительным к чеством ур внения (11) является то, что по ср внению с ур внением (3) оно более приспособлено к решению в жных пр ктических 3 д ч обр ботки д нных

. оэтомуз д ч построения полиноми льных ппроксим ций з кон рри- онвея (6) для ди п зон пр ктических зн чений чисел ейнольдс является кту льной.

оэффициенты полиноми льных ппроксим ций з кон рри- онвея предл г ется p ссчитыв ть в среде MS Excel следующим обр зом. н ч ле, н 1-ом ш ге, для з д нного н бор п р метров $\beta, k_{m r}$ и $\alpha$ т булируем вспомог тельную функцию $Y=Y(\operatorname{Re})$ :

$$
Y=\frac{\frac{k}{k_{9 \phi \phi}}-1}{\operatorname{Re}}=\frac{(1+\beta \cdot \operatorname{Re})^{\alpha}-\left[k_{m r} \cdot(1+\beta \cdot \operatorname{Re})^{\alpha}+1-k_{m r}\right]}{\operatorname{Re} \cdot\left[k_{m r} \cdot(1+\beta \cdot \operatorname{Re})^{\alpha}+1-k_{m r}\right]} .
$$

лее, н 2-ом ш ге, средств ми MS Excel [9] строим линию тренд $Y=c_{1}+c_{2} \cdot \operatorname{Re}+c_{3} \cdot \operatorname{Re}^{2}+\ldots$ с использов нием встроенной функции вид изменения $Y$; ди п зон изменения $\left.\operatorname{Re}^{\wedge}\{1 ; 2 ; 3 ; 4\}\right)$ и н ходим коэффициенты $c_{1}, c_{2}, c_{3}, \ldots$

пример, для п р метров $\alpha=2, \beta=1$ и $k_{m r}=0,1 ; 0,2 ; 0,5$ коэффициенты ппроксимирующего функцию (6) полином 5-ой степени, н йденные по опис нному лгоритму, р вны ук 3 нным в т блице зн чениям.

оэффициенты ппроксимирующего з кон рри- онвея (6) полином

\begin{tabular}{|c|c|c|c|}
\hline \multirow{2}{*}{ оэффициенты } & \multicolumn{3}{|c|}{$\mathrm{p}$ метры: $\alpha=2 ; \beta=1$} \\
\cline { 2 - 4 } & $k_{m r}=0,1$ & $k_{m r}=0,2$ & $k_{m r}=0,5$ \\
\hline$c_{1}$ & 2,4060 & 1,6419 & 0,6053 \\
\hline$c_{2}$ & $-0,2591$ & $-0,2443$ & $-0,1083$ \\
\hline$c_{3}$ & 0,0131 & 0,0155 & 0,0076 \\
\hline$c_{4}$ & $-3,1 \cdot 10^{-4}$ & $-4,30 \cdot 10^{-4}$ & $-2,22 \cdot 10^{-4}$ \\
\hline$c_{5}$ & $2,75 \cdot 10^{-6}$ & $4,29 \cdot 10^{-6}$ & $2,29 \cdot 10^{-6}$ \\
\hline
\end{tabular}

ост точн я для пр ктических целей точность ппроксим ции з кон рри- онвея при перечисленных зн чениях его п р метров $\alpha, \beta$ и $k_{m r}$ н глядно иллюстрируется гр фик ми 
н рис. 4, где приведены гр фики оригин л (6) и гр фики ппроксимирующих полиномов 5-ой степени. озвр щ ясь к гр фик м н рис. 1, отметим, что в отличие от з конов орхгеймер и рри- онвея в 3 коне уршин . . выделяется н ч льный уч сток $\operatorname{Re} \leq R_{1}$ м лых чисел ейнольдс , н котором имеет место линейн я фильтр ция по з кону рси. ля того чтобы ввести в 3 кон рри- онвея н ч льный уч сток $\operatorname{Re} \leq R_{1}$ м лых чисел ейнольдс , ур внение (6) вторы предл г ют з менить следующим ур внением:

$$
\frac{k}{k_{\text {эфф }}}=1+\left(\frac{1}{k_{m r}}-1\right) \cdot \operatorname{th}\left(\frac{\mathrm{Re}}{\operatorname{Re}_{\kappa p}}\right)^{\alpha} .
$$

зменение эффективной прониц емости пористой среды по гиперт нгенс льному з кону проиллюстриров но н рис. 5.

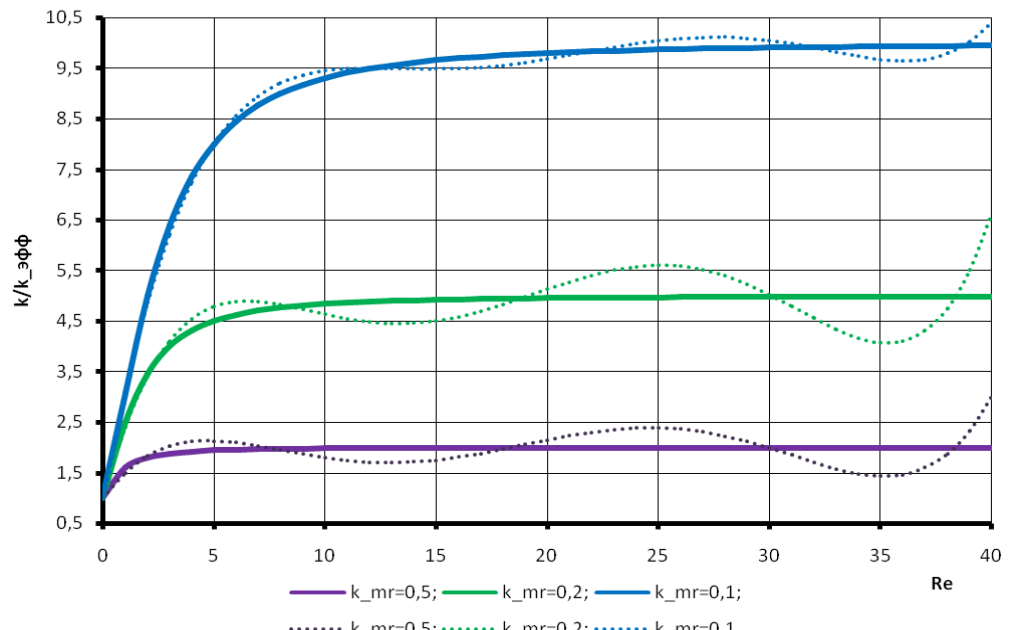

ис. 4. р внение эффективных прониц емостей пористой среды по з кону рри- онвея(6) с их ппроксим ционными модеяями (10)

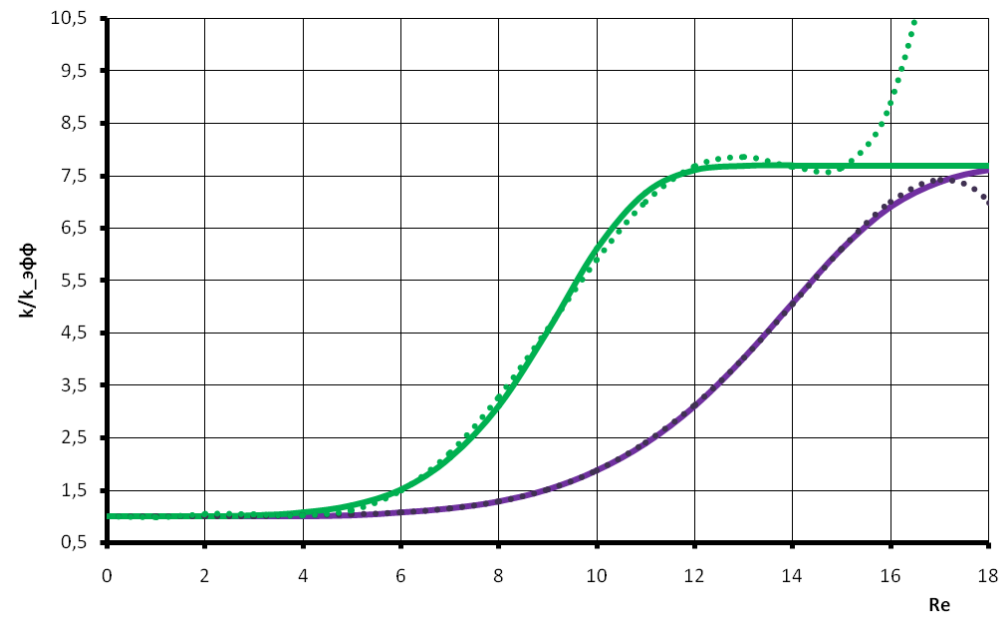

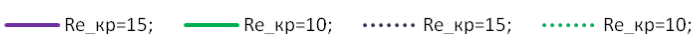

Ис. 5. зменение эффективной прониц емости пористой среды по гиперт нгенс льному з кону (13) (сплошные линии) и по ппроксим ционным моделям (10) гиперт нгенс льного з кон (точечные линии). $\quad$ р метры: $\alpha=5 ; k_{m r}=0,13$ 
изический смысл фильтр ционных п р метров $k_{m r}$ и $\alpha$ в гиперт нгенс льном $з$ коне (13) т кой же, к к и у одноименных п р метров в з коне рри- онвея. р метр $k_{m r}$ д ет предельное миним льное зн чение пропускной способности пористой среды при высоких скоростях фильтр ции: $k_{\text {эфф }} \underset{\operatorname{Re} \rightarrow \infty}{\longrightarrow} k k_{m r}, \quad$ п р метр $\alpha$ д е ет скорость п дения пропускной способности пористой среды: чем больше $\alpha$, тем быстрее эффективн я прониц емость приближ ется к своей симптотической миним льной величине.

ким обр зом, приемлем я точность ппроксим ционных моделей (10), иллюстрируем я гр фик ми н рисунк х 4 и 5, позволяет рекомендов ть к пр ктическому применению в к честве универс льного $з$ кон фильтр ции г $з$ (жидкости) при с мых широких ре льных ди п зон х зн чений фильтр ционных чисел ейнольдс ур внение (11). оэффициенты $c_{m}$ ур внения (11) следует р ссм трив ть к к м тери льные конст нты пористой среды, подлеж щие определению н основ нии обр ботки д нных · к ждого тип пористой среды может быть, в з висимости от геометрических особенностей строения порового простр нств и мех нических свойств скелет пористой среды, свое количество и свои типовые зн чения м тери льных конст нт $c_{m}$.

оложительным к чеством ур внения (11), в отличие от других з конов (6), (7), (13), является то, что его форм позволяет р зр бот ть модифициров нную методику применяемых сейч с кл ссических способов обр ботки д нных под средств т бличного процессор MS Excel [9] и уточнять основные фильтр ционно-емкостные х р ктеристики продуктивных пл стов.

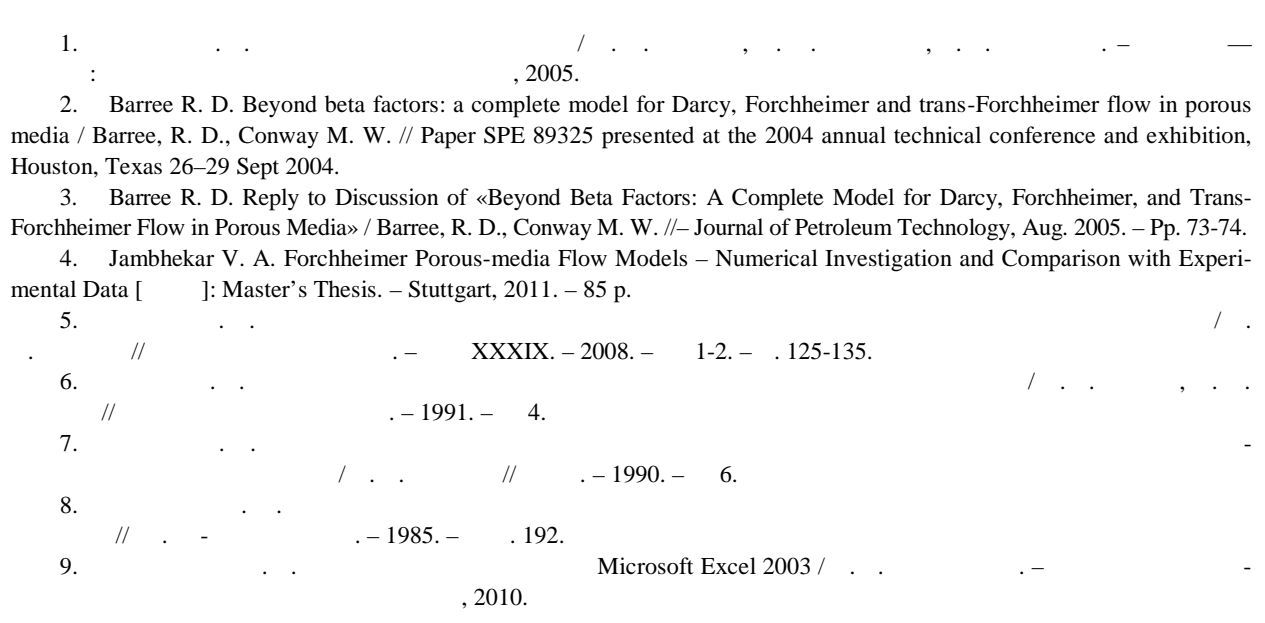

2. Barree R. D. Beyond beta factors: a complete model for Darcy, Forchheimer and trans-Forchheimer flow in porous media / Barree, R. D., Conway M. W. // Paper SPE 89325 presented at the 2004 annual technical conference and exhibition, Houston, Texas 26-29 Sept 2004.

3. Barree R. D. Reply to Discussion of «Beyond Beta Factors: A Complete Model for Darcy, Forchheimer, and TransForchheimer Flow in Porous Media» / Barree, R. D., Conway M. W. //- Journal of Petroleum Technology, Aug. 2005. - Pp. 73-74.

4. Jambhekar V. A. Forchheimer Porous-media Flow Models - Numerical Investigation and Comparison with Experimental Data [ екст]: Master's Thesis. - Stuttgart, 2011. - 85 p.

5. уршин . . кономерности изменения прониц емости пористых сред при фильтр ционных течениях / уршин // ченые з писки . - ом XXXIX. - 2008. - № 1-2. - . 125-135.

6. ерм н . . ильтр ция г з в пористых сред х при больших гр диент х д вления / . . ерм н, . . уршин // зов я промышленность. - 1991. - № 4.

7. уршин . . сследов ние фильтр ционных течений г з через обр зцы из кернов горных пород н режим х с критическим истечением / . . . уршин // _ . - 1990. - № 6.

8. орот ев . . сследов ние гр ниц применимости линейного з кон фильтр ции рси кустическим способом // р. ин-т и . -1985. - ып. 192.

9. пиридонов . . сширенные возможности Microsoft Excel 2003 / . . пиридонов. - ентр дист нционных обр зов тельных технологий , 2010.

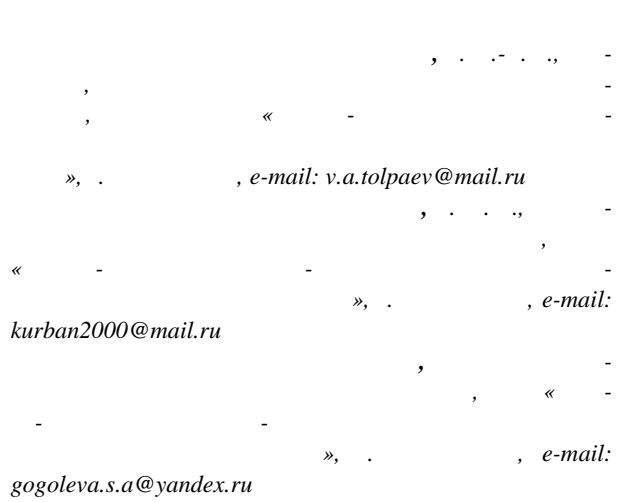

Information about the authors

Tolpaev V. A., Doctor of Physics and Mathematics, professor, head of the laboratory of underground hydrodynamics, OJSC «North Caucasus Research and Designing Institute of Natural Gases», Stavropol, e-mail: v.a.tolpaev@mail.ru

Ahmedov K. S., Candidate of Science in Engineering, head of the department for new information technologies, OJSC «North Caucasus Research and Designing Institute of Natural Gases», Stavropol, e-mail: kurban2000@mail.ru

Gogoleva S. A., scientific worker of the laboratory of underground hydrodynamics, OJSC «North Caucasus Research and Designing Institute of Natural Gases», Stavropol, e-mail: gogoleva.s.a@yandex.ru 